\title{
Front Matter: Volume 7395
}

, "Front Matter: Volume 7395," Proc. SPIE 7395, Plasmonics: Nanoimaging, Nanofabrication, and their Applications V, 739501 (22 September 2009); doi: $10.1117 / 12.846112$

SPIE Event: SPIE NanoScience + Engineering, 2009, San Diego, California, United SPIE. States 


\section{PROCEEDINGS OF SPIE}

\section{Plasmonics: Nanoimaging, Nanofabrication, and their Applications $V$}

Satoshi Kawata

Vladimir M. Shalaev

Din Ping Tsai

Editors

2-6 August 2009

San Diego, California, United States

Sponsored and Published by

SPIE 
The papers included in this volume were part of the technical conference cited on the cover and title page. Papers were selected and subject to review by the editors and conference program committee. Some conference presentations may not be available for publication. The papers published in these proceedings reflect the work and thoughts of the authors and are published herein as submitted. The publisher is not responsible for the validity of the information or for any outcomes resulting from reliance thereon.

Please use the following format to cite material from this book:

Author(s), "Title of Paper," in Plasmonics: Nanoimaging, Nanofabrication, and their Applications $V$, edited by Satoshi Kawata, Vladimir M. Shalaev, Din Ping Tsai, Proceedings of SPIE Vol. 7395 (SPIE, Bellingham, WA, 2009) Article CID Number.

ISSN 0277-786X

ISBN 9780819476852

Published by

SPIE

P.O. Box 10, Bellingham, Washington 98227-0010 USA

Telephone +1 3606763290 (Pacific Time) · Fax +1 3606471445

SPIE.org

Copyright (C) 2009, Society of Photo-Optical Instrumentation Engineers

Copying of material in this book for internal or personal use, or for the internal or personal use of specific clients, beyond the fair use provisions granted by the U.S. Copyright Law is authorized by SPIE subject to payment of copying fees. The Transactional Reporting Service base fee for this volume is $\$ 18.00$ per article (or portion thereof), which should be paid directly to the Copyright Clearance Center (CCC), 222 Rosewood Drive, Danvers, MA 01923. Payment may also be made electronically through CCC Online at copyright.com. Other copying for republication, resale, advertising or promotion, or any form of systematic or multiple reproduction of any material in this book is prohibited except with permission in writing from the publisher. The CCC fee code is 0277-786X/09/\$18.00.

Printed in the United States of America.

Publication of record for individual papers is online in the SPIE Digital Library.

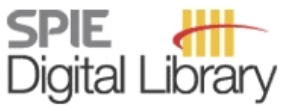

SPIEDigitalLibrary.org

Paper Numbering: Proceedings of SPIE follow an e-First publication model, with papers published first online and then in print and on CD-ROM. Papers are published as they are submitted and meet publication criteria. A unique, consistent, permanent citation identifier (CID) number is assigned to each article at the time of the first publication. Utilization of CIDs allows articles to be fully citable as soon they are published online, and connects the same identifier to all online, print, and electronic versions of the publication. SPIE uses a six-digit CID article numbering system in which:

- The first four digits correspond to the SPIE volume number.

- The last two digits indicate publication order within the volume using a Base 36 numbering system employing both numerals and letters. These two-number sets start with 00, 01, 02, 03, 04, $05,06,07,08,09,0 A, 0 B \ldots 0 Z$, followed by 10-1Z, 20-2Z, etc.

The CID number appears on each page of the manuscript. The complete citation is used on the first page, and an abbreviated version on subsequent pages. Numbers in the index correspond to the last two digits of the six-digit CID number. 


\section{Contents}

ix Conference Committee

xiii Introduction

$\mathrm{xV} \quad$ Sub-nanometer resolution for the inspection of reflective surfaces using white light (Plenary Paper) [7405-37]

W. Jüptner, T. Bothe, Bremer Institut für angewandte Strahltechnik (Germany)

\section{NANO FABRICATION AND LITHOGRAPHY}

739503 Molecular manipulation and nanofabrication using local polarization in optical near-fields (Invited Paper) [7395-02]

Y. Ohdaira, K. Shinbo, A. Baba, K. Kato, F. Kaneko, Niigata Univ. (Japan)

739505 Nanoscale photopolymerization induced by the enhanced optical near field of metallic nanoparticles [7395-04]

C. Deeb, A.-L. Baudrion, S. Jradi, J. Plain, Lab. de Nanotechnologie et d'Instrumentation Optique, CNRS, Univ. de Technologie de Troyes (France); A. Bouhelier, Institut Carnot de Bourgogne, CNRS, Univ. de Bourgogne (France); O. Soppera, L. Balan, H. Ridaoui, Dept. de Photochimie Générale, CNRS, Univ. de Haute Alsace (France); P. Royer, R. Bachelot, Lab. de Nanotechnologie et d'Instrumentation Optique, CNRS, Univ. de Technologie de Troyes (France)

739507 Fabrication of III-V semiconductor quantum dots (Invited Paper) [7395-06]

K. Akahane, N. Yamamoto, National Institute of Information and Communications Technology (Japan)

\section{PLASMONIC SPECTROSCOPY II}

$7395 \mathrm{OB}$ Surface plasmon polariton enhanced fluorescence from quantum dots on nanostructured metal surfaces (Invited Paper) [7395-10]

E. Hwang, C. C. Davis, I. I. Smolyaninov, Univ. of Maryland, College Park (United States)

7395 OF Confocal and near-field spectroscopic investigation of P3HT:PCBM organic blend film upon thermal annealing [7395-15]

X. Wang, D. Zhang, K. Braun, Eberhard Karls Univ. Tübingen (Germany); H.-J. Egelhaaf, Konarka Technologies GmbH (Germany); A. J. Meixner, Eberhard Karls Univ. Tübingen (Germany)

\section{NANO IMAGING I}

7395 OG Ultrafast energy flow in hybrid plasmonic materials (Invited Paper) [7395-16]

G. P. Wiederrecht, J. Hranisavljevic, Argonne National Lab. (United States) 
$73950 \mathrm{M}$ Plasmonic nanoparticle based biosensing: experiments and simulations (Invited Paper) [7395-23]

T. Sannomiya, C. Hafner, J. Vörös, ETH Zürich (Switzerland)

739500 Exploiting plasmonics in biosensing and bioimaging: monitoring cell receptors with surface enhanced spectroscopy and microscopy [7395-25]

L.-L. Tay, D. Kennedy, J. Hulse, J. P. Pezaki, J. Fraser, X. Wu, National Research Council Canada (Canada)

\section{MANIPULATION OF PLASMONIC EFFECT II}

7395 OT Control light propagation and polarization with plasmons for surface-enhanced Raman scattering (Invited Paper) [7395-32]

H. Wei, Z. Li, Y. Fang, Beijing National Lab. for Condensed Matter Physics (China) and Institute of Physics (China); F. Hao, Rice Univ. (United States); T. Shegai, T. Dadosh, Weizmann Institute of Science (Israel); Y. Huang, Beijing National Lab. for Condensed Matter Physics (China) and Institute of Physics (China); W. Wang, Beijing National Lab. for Condensed Matter Physics (China), Institute of Physics (China), and Central Univ. for Nationalities (China); Z. Zhang, Oak Ridge National Lab. (United States) and Univ. of Tennessee (United States); G. Haran, Weizmann Institute of Science (Israel); P. Nordlander, Rice Univ. (United States); H. Xu, Beijing National Lab. for Condensed Matter Physics (China), Institute of Physics (China), and Lund Univ. (Sweden)

7395 OU Gap plasmon waveguide with a stub: structure for a wavelength selective device [7395-33] M. Haraguchi, K. Iuchi, H. Sokabe, T. Okuno, T. Okamoto, M. Fukui, Univ. of Tokushima (Japan); K. Okamoto, S. Tagawa, Osaka Univ. (Japan)

$7395 \mathrm{OV}$ Transient surface plasmon polariton launched by a metal subwavelength slit scattering [7395-34]

Y. Gravel, Y. Sheng, Univ. Laval (Canada)

7395 OW Molecular active plasmonics: controlling plasmon resonances with molecular machines [7395-35]

Y. B. Zheng, The Pennsylvania State Univ. (United States); Y.-W. Yang, Northwestern Univ. (United States); L. Jensen, The Pennsylvania State Univ. (United States); L. Fang, Northwestern Univ. (United States); B. K. Juluri, The Pennsylvania State Univ. (United States); A. H. Flood, Indiana Univ. (United States); P. S. Weiss, The Pennsylvania State Univ. (United States); J. F. Stoddart, Northwestern Univ. (United States); T. J. Huang, The Pennsylvania State Univ. (United States)

\section{PLASMONICS I}

7395 OY Sensitivities and amplification of surface plasmons (Invited Paper) [7395-37] P. Berini, Univ. of Ottawa (Canada) and Spectalis Corp. (Canada); I. De Leon, Univ. of Ottawa (Canada) 
$73950 Z$ Plasmonics: nonlinear optics, negative phase, and transformable transparency (Invited Paper) [7395-38]

A. K. Popov, Univ. of Wisconsin, Stevens Point (United States); S. A. Myslivets, Siberian Federal Univ. (Russian Federation) and Kirensky Institute of Physics (Russian Federation);

V. M. Shalaev, Purdue Univ. (United States)

\section{PLASMONICS II}

739512 Coupling light to a localized surface plasmon-polariton (Invited Paper) [7395-41]

M. Agio, G. Zumofen, N. M. Mojarad, V. Sandoghdar, ETH Zürich (Switzerland)

\section{PLASMONICS III}

739517 Nanoparticle optics of complex nanorod architectures (Invited Paper) [7395-46]

K. L. Shuford, Oak Ridge National Lab. (United States); S. Park, Sungkyunkwan Univ. (Korea, Republic of)

739518 Modeling near-field properties of plasmonic nanoparticles: a surface integral approach (Invited Paper) [7395-47]

A. M. Kern, O. J. F. Martin, Ecole Polytechnique Fédérale de Lausanne (Switzerland)

739519 Defect state dampening of surface plasmons in AU-YSZ nanocomposites [7395-48]

P. H. Rogers, M. A. Carpenter, Univ. at Albany (United States)

\section{PLASMONIC METAMATERIALS I}

$7395 \mathrm{IF}$ Optical activity in metal and dielectric planar chiral gratings (Invited Paper) [7395-54] K. Konishi, N. Kanda, The Univ. of Tokyo (Japan) and CREST-JST (Japan); B. Bai, Univ. of JoensuU (Finland); X. Meng, Univ. of JoensuU (Finland) and Tsinghua Univ. (China); P. Karvinen, J. Turunen, Y. P. Svirko, Univ. of Joensuu (Finland); M. Kuwata-Gonokami, The Univ. of Tokyo (Japan) and CREST-JST (Japan)

\section{PLASMONIC METAMATERIALS II}

$7395 \mathrm{1H} \quad$ Manipulating the optical transparency of anisotropic metamaterials with magnetic field and liquid crystals: influence of the nanostructures shape (Invited Paper) [7395-56] Y. M. Strelniker, Bar-llan Univ. (Israel); D. J. Bergman, Tel Aviv Univ. (Israel); Y. Fleger, M. Rosenbluh, Bar-llan Univ. (Israel); D. G. Stroud, The Ohio State Univ. (United States); A. O. Voznesenskaya, St. Petersburg State Univ. of Information Technologies, Mechanics and Optics (Russian Federation)

$739511 \quad$ Experimental investigation of Fang's Ag superlens suitable for integration [7395-57] C. Jeppesen, Technical Univ. of Denmark (Denmark); R. B. Nielsen, Technical Univ. of Denmark (Denmark) and Purdue Univ. (United States); S. Xiao, N. A. Mortensen, Technical Univ. of Denmark (Denmark); A. Boltasseva, Purdue Univ. (United States); A. Kristensen, Technical Univ. of Denmark (Denmark) 
$7395 \mathrm{lJ} \quad$ Loss monitoring in resonant photon tunneling through metal and dielectric multi-layer metamaterials [7395-58]

M. Matsunaga, S. Tomita, T. Yokoyama, H. Yanagi, Nara Institute of Science and Technology (Japan)

\section{PLASMONIC METAMATERIALS III}

7395 1K Magnetic resonance in stratified metal-dielectric metamaterials (Invited Paper) [7395-59]

R. Watanabe, A. S. Vioktalamo, T. Ishihara, Tohoku Univ. (Japan)

$73951 \mathrm{~L}$ Diversity of optical indices in stratified metal-dielectric metamaterials (Invited Paper) [7395-60]

M. Iwanaga, National Institute for Materials Science (Japan)

\section{NANOPLASMONIC APPLICATIONS I}

7395 IR Effect of surrounding medium on the optical properties of a two layer silver film (Invited Paper) [7395-66]

W. Yang, J. Reed, S. Zou, Univ. of Central Florida (United States)

7395 is Quantitative amplification of surface enhanced Raman scattering through plasmonic coupling in controlled nanoparticle assemblies (Invited Paper) [7395-67]

S.-Y. Chen, A. A. Lazarides, Duke Univ. (United States)

7395 IT Transmission through Kerr media barriers within waveguides and circuits (Invited Paper) [7395-68]

A. R. McGurn, Western Michigan Univ. (United States)

\section{NANOPLASMONIC APPLICATIONS II}

$73951 \mathrm{U}$ Sensoric applications based on plasmonic effects at metal nanoparticles (Invited Paper) [7395-69]

T. Schneider, A. Steinbrück, M. Löchner, A. Csáki, W. Fritzsche, IPHT Jena (Germany)

7395 IV Nanoplasmonic resonance energy transfer spectroscopic pH imaging (Invited Paper) [7395-70]

G. L. Liu, Univ. of Illinois at Urbana-Champaign (United States)

\section{POSTER SESSION}

7395 2B Fast surface plasmon-polariton-based optical phase modulator [7395-83]

O. Guilatt, Ben-Gurion Univ. of the Negev (Israel); B. Apter, Holon Institute of Technology (Israel); U. Efron, Ben-Gurion Univ. of the Negev (Israel) and Holon Institute of Technology (Israel) 
7395 2C Problem of $x$-ray synchrotron beam collimation by zone plate [7395-87]

A. Kuyumchyan, Institute of Microelectronics Technology (Russian Federation); V. Kohn, Russian Research Ctr. Kurchatov Institute (Russian Federation); A. Snigirev, I. Snigireva, European Synchrotron Radiation Facility (France); M. Grigorev, A. Kouznetsov, Institute of Microelectronics Technology (Russian Federation)

Author Index 
Downloaded From: https://www.spiedigitallibrary.org/conference-proceedings-of-spie on 26 Apr 2023

Terms of Use: https://www.spiedigitallibrary.org/terms-of-use 


\title{
Conference Committee
}

\author{
Symposium Chairs
}

David L. Andrews, University of East Anglia Norwich (United Kingdom) James G. Grote, Air Force Research Laboratory (United States)

Conference Chairs

Satoshi Kawata, Osaka University (Japan)

Vladimir M. Shalaev, Purdue University (United States)

Din Ping Tsai, National Taiwan University (Taiwan)

Program Committee

Harry A. Atwater, Jr., California Institute of Technology (United States)

David J. Bergman, Tel Aviv University (Israel)

Sergey I. Bozhevolnyi, Aalborg Universitet (Denmark)

Nader Engheta, University of Pennsylvania (United States)

Nicholas X. Fang, University of Illinois at Urbana-Champaign (United States)

Jochen Feldmann, Ludwig-Maximilians-Universität München

(Germany)

Naomi J. Halas, Rice University (United States)

Teruya Ishihara, Tohoku University (Japan)

Fritz Keilmann, Max-Planck-Institut für Biochemie (Germany)

Pieter G. Kik, College of Optics and Photonics, University of Central Florida (United States)

Victor I. Klimov, Los Alamos National Laboratory (United States)

Joachim R. Krenn, Karl-Franzens-Universität Graz (Austria)

Aaron Lewis, Nanonics Imaging Ltd. (Israel)

Olivier J. F. Martin, Swiss Federal Institute of Technology (Switzerland)

Martin Moskovits, University of California, Santa Barbara (United States)

Peter J. Nordlander, Rice University (United States)

Masaya Notomi, NTT Basic Research Laboratories (Japan)

Lukas Novotny, University of Rochester (United States)

Motoichi Ohtsu, The University of Tokyo (Japan)

Joseph W. Perry, Georgia Institute of Technology (United States)

Vahid H. Sandoghdar, Eidgenossische Technische Hochschule

(Switzerland)

George C. Schatz, Northwestern University (United States)

Tigran V. Shahbazyan, Jackson State University (United States)

Mark I. Stockman, Georgia State University (United States)

Cheng Sun, Northwestern University (United States)

Prabhat Verma, Osaka University (Japan) 
Xiang Zhang, University of California, Berkeley (United States)

Nikolay I. Zheludev, University of Southampton (United Kingdom)

\section{Session Chairs}

1 Nano Fabrication and Lithography

Alexandra E. Boltasseva, Purdue University (United States)

Richard P. Van Duyne, Northwestern University (United States)

2 Plasmonic Spectroscopy

Alexandra E. Boltasseva, Purdue University (United States)

3 Plasmonic Spectroscopy II

Gary P. Wiederrecht, Argonne National Laboratory (United States)

$4 \quad$ Nano Imaging I

Takuo Tanaka, The Institute of Physical and Chemical Research (Japan)

$5 \quad$ Nano Imaging II

Martin Moskovits, University of California, Santa Barbara (United States)

$6 \quad$ Nanosensing

Martin Moskovits, University of California, Santa Barbara (United States)

$7 \quad$ Manipulation of Plasmonic Effect I

Vladimir M. Shalaev, Purdue University (United States)

8 Manipulation of Plasmonic Effect II

Stefan A. Maier, Imperial College London (United Kingdom)

9 Plasmonics 1

Din Ping Tsai, National Taiwan University (Taiwan)

10 Plasmonics II

Peter J. Nordlander, Rice University (United States)

11 Plasmonics III

Satoshi Kawata, Osaka University (Japan)

12 Plasmonic Metamaterials I

Mikhail A. Noginov, Norfolk State University (United States)

13 Plasmonic Metamaterials II

Harry A. Atwater, Jr., California Institute of Technology (United States) 
14 Plasmonic Metamaterials III

Nader Engheta, University of Pennsylvania (United States)

15 Nanoplasmonic Applications I

Anatoly V. Zayats, Queen's University Belfast (United Kingdom)

16 Nanoplasmonic Applications II

Prabhat Verma, Osaka University (Japan)

17 Nanoplasmonic Applications III

Zhaowei Liu, University of California, San Diego (United States)

18 Nanoplasmonic Applications IV

Wolfgang Fritzsche, IPHT Jena (Germany)

19 Nanoplasmonic Applications V

Mark L. Brongersma, Stanford University (United States) 
Downloaded From: https://www.spiedigitallibrary.org/conference-proceedings-of-spie on 26 Apr 2023

Terms of Use: https://www.spiedigitallibrary.org/terms-of-use 


\section{Introduction}

This proceedings contains papers presented at the 2009 SPIE Optics \& Photonics conference on Plasmonics: Nanoimaging, Nanofabrication, and their Applications $\vee$ held in San Diego, California, 2-6 August, 2009. This annual event was a great opportunity where specialists from diverse research areas exchanged the latest progress on plasmonics and explored the future prospect of research.

This conference was divided into 19 sessions. Eighty-two oral, plenary, and poster presentations broadened the perspective of all our attendees. In the first session, presentations were related to nanofabrication and lithography, such as nanoscale fabrication technique of three-dimensional metal structures for plasmonic metamaterials, making plasmonic structures for nano- and meta-photonics: fabrication methods and challenges, and fabrication of III-V semiconductor quantum dots.

The second and third sessions focused on plasmonic spectroscopy, including plasmonics in UV for nano-imaging and analysis, nanoscale tuneable light source, and spectroscopic TPL mapping of plasmonic systems.

The fourth and fifth sessions focused on nano-imaging, containing imaging ultrafast energy and charge flow in hybrid plasmonic materials, and plasmonic mediated optical imaging at nanoscale.

The sixth, seventh, and eighth sessions probed into nanosensing and manipulation of plasmonic effect, covering from highly sensitive molecular sensing using pyramidal plasmonic crystals, and control of absorption loss in metallic films, to enhanced rates and high directivity for single emitters with optical antennas.

The ninth, tenth, and eleventh sessions focused on plasmonics, nanoplasmonics beyond the dipolar regime: probing bright and dark plasmonic modes using optical and electron spectroscopies, plasmons in strongly coupled metallic nanostructures, unconventional plasmonic materials and emerging applications.

The twelfth, thirteenth, and fourteenth sessions dealt with the recent hot topic plasmonic metamaterials, including plasmonic metamaterials: single layer negative index materials, broadband absorbers and tunable split ring resonators, optical activity in metal and dielectric planar chiral gratings, plasmonic nanorod metamaterial with enhanced biosensing functionalities, and magnetic resonance in stratified metal-dielectric metamaterials.

The fifteenth to the nineteenth sessions were devoted to nanoplasmonic applications, where a great number of intriguing presentations on magnetically 
coupled nanoscale channels in optical epsilon-near-zero (ENZ) substrates, sensoric applications based on plasmonic effects at metal nanoparticles, shaping the optical and thermal properties of plasmonic nanostructures for biological applications, plasmonic manipulation of the local density of states: optical antennas, corrals, and a plasmon mirage, and sub-wavelength plasmonic lasers were reported.

During the five conference days, we learned various perspectives ranging from fundamental to edgy research. These valuable research exchanges and discussions will certainly contribute to the future development of nanoscience. We extend our sincerest respect and gratitude to every contributor of conference 7395 -it is you who set up a perfect model for the conference.

Please notice that some of the papers listed above were published elsewhere; therefore, this proceedings only includes partial contributions of the conference.

Satoshi Kawata Vladimir M. Shalaev Din Ping Tsai 